\title{
Solvent- and Catalyst-Free Three-Component Reaction with $\beta$-Ketoamides for the Stereoselective One-Pot Access to 1,4-Diazepines
}

\author{
Enrique Sotoca, Thierry Constantieux, * Jean Rodriguez* \\ Institut des Sciences Moléculaires de Marseille, iSm2 CNRS UMR 6263, Aix-Marseille Université, \\ Centre Saint Jérôme, Service 531, 13397 Marseille Cedex 20, France \\ Fax +33(4)91288841; E-mail: jean.rodriguez@univ-cezanne.fr \\ Received 6 March 2008
}

Abstract: ' The stereoselective one-pot synthesis of polysubstituted
1,4-diazepine derivatives has been achieved via a new solvent- and
catalyst-free multicomponent domino reaction from $\beta$-ketoamides.
This green and experimentally simple sequence is conducted from
easily accessible achiral starting materials, does not require any
harmful reagents, and results in a high increase in molecular com-
plexity and diversity. Moreover, water is the only byproduct liber-
ated during the reaction.

Key words: multicomponent reaction, 1,4-diazepines, $\beta$-ketoamides, solvent-free reaction, green chemistry

Multicomponent reactions (MCR), ${ }^{1}$ involving domino processes, ${ }^{2}$ have emerged as powerful tools for the creation of molecular complexity and diversity ${ }^{3}$ from simple substrates, while combining economic aspects ${ }^{4,5}$ with environmental ones. ${ }^{6}$ This concept is now a well-established approach for the development of new heterocyclic structures of both synthetic and medicinal interests, and has been the center of much recent efforts. If in addition these transformations can efficiently be run with recyclable heterogeneous catalysts, or even better without any solvent ${ }^{7}$ and catalyst, the result would be nearly an ideal process in terms of both greenness and simplicity. ${ }^{8}$ In this context and in conjunction with our ongoing interest for the specific reactivity of easily accessible 1,3-dicarbonyl compounds, ${ }^{9}$ we have recently reported the use of molecular sieves as heterogeneous catalysts for Michael addition initiated multicomponent domino transformations of $\beta$-ketoesters, $\beta$-diketones, and $\beta$-ketoamides in the presence of unsaturated aldehydes and functionalized primary amines of type $\mathbf{1}$, for the stereoselective synthesis of polycyclic heterocycles. ${ }^{10}$ Moreover, part of our efforts have been directed towards the development of the synthetic potential of 1,3-dicarbonyls using both the $\alpha$ - and $\gamma$-reactive sites, leading to regio-, chemo-, and stereoselectively valuable $\alpha, \gamma$-difunctionalized $\alpha$-ketoesters and amides of type $\mathbf{5}^{11}$ By combining these two aspects of the reactivity of such substrates, we expected that the multicomponent reaction between 1,2-diamines 1, 1,3-dicarbonyls $\mathbf{2}$, and aromatic aldehydes $\mathbf{3}$ might lead to the formation of seven-membered ring systems with a 1,4-diazepine skeleton $\mathbf{4}$ (Scheme 1). The expected heterocycles 4 may result from a formal aza-Michael addition-dehydrative cyclization sequence between 1,2-diamines $\mathbf{1}$ and $\gamma$-arylidenes $\mathbf{5}$, obtained through a $\gamma$-functionalization of 1,3-dicarbonyls 2 as previously reported. ${ }^{12}$

Quite surprisingly, the high synthetic potentialities of $\beta$ ketoamides in MCR have not stimulated much interest so far. Only recently, our group has proposed efficient multicomponent accesses to original 2,6-DABCO ${ }^{10 \mathrm{c}}$ and $\alpha$ alkylated- $\gamma$-arylidene- $\beta$-ketoamides. ${ }^{11}$ Keeping these precedents in mind, we present in this communication the direct stereoselective one-pot, three-component conversion of $\beta$-ketoamides into 1,4-diazepines under solvent- and catalyst-free conditions. ${ }^{13}$ From a biological point of view, heterocycles of type $\mathbf{4}$ represent an alternative to the classical benzodiazepine scaffolds. ${ }^{14}$ Moreover, our synthetic strategy constitutes a good example of function-oriented design of molecules with therapeutic potential that can be made in a step- and atom-economical fashion. ${ }^{15}$

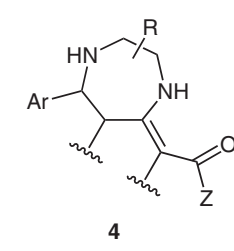

Scheme 1

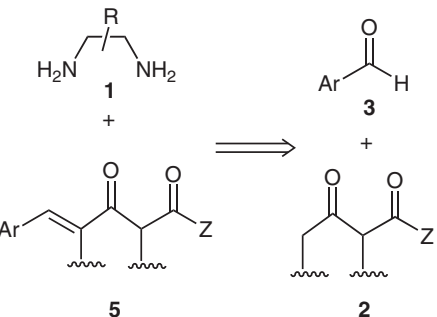

In order to validate our synthetic plan, we ran two test experiments involving 1,2-ethylene-diamine (1a), $\beta$-ketoamide 2a, and benzaldehyde (3a) both under our previously standard MCR conditions, ${ }^{10}$ that is, in refluxing toluene in the presence of $4 \AA$ molecular sieves, and in the absence of solvent and catalyst. After completion of the reaction, the desired product $4 \mathbf{a}$ was formed and isolated with $37 \%$ and $19 \%$ yield, respectively (Scheme 2, Table 1, entry 1).

Although low yield was observed, it is noteworthy that product 4a was formed under solvent- and catalyst-free conditions. So, we decided to study the general applicability of this transformation by first varying the nature of the aromatic aldehyde. Thus, using $p$-nitrobenzaldehyde (3b) and $p$-fluorobenzaldehyde (3c), the corresponding products were isolated with moderate to good yields (entries 2 


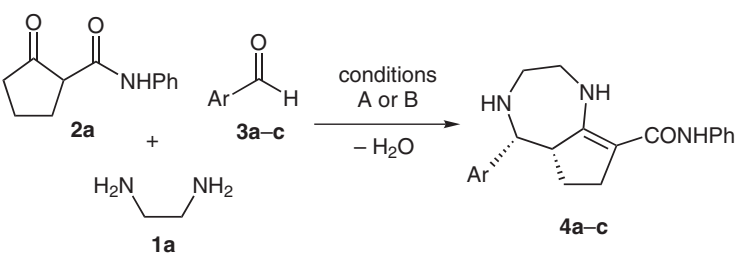

Scheme 2

Table 1 Synthesis of Compounds 4

\begin{tabular}{llll}
\hline Entry & Ar & $\begin{array}{c}\text { Yield }(\%)^{\mathrm{c}} \\
\text { Method } \mathrm{A}^{\mathrm{a}}\end{array}$ & Method B $^{\mathrm{b}}$ \\
\hline 1 & $\mathrm{Ph}(\mathbf{3 a})$ & 37 & 19 \\
2 & $4-\mathrm{O}_{2} \mathrm{NC}_{6} \mathrm{H}_{4}(\mathbf{3 b})$ & 26 & 31 \\
3 & $4-\mathrm{FC}_{6} \mathrm{H}_{4}(\mathbf{3 c})$ & 64 & 77 \\
\hline
\end{tabular}

a Conditions: $4 \AA$ A $\mathrm{MS}$, toluene, $110{ }^{\circ} \mathrm{C}, 24 \mathrm{~h}$.

${ }^{\mathrm{b}}$ Conditions: $120^{\circ} \mathrm{C}, 4 \mathrm{~h}$.

${ }^{\mathrm{c}}$ Isolated yield after flash chromatography.

and 3, Table 1). Crude products were easily obtained with acceptable chemical purity ${ }^{16}$ by simple dilution of the reaction mixture with ethyl acetate and filtration through a short pad of Celite. Interestingly enough, we were pleased to note that yields were higher under green conditions compared to more standard MCR conditions, and time reactions were significantly reduced from 24 hours to 4 hours. Moreover, product $\mathbf{4 a - c}$ were obtained as a single diastereomer, identified as the 5,6-cis-isomer, ${ }^{17}$ making this overall sequence a stereoselective and environmentally friendly access to 1,4-diazepine skeletons, starting from simple and very easily accessible achiral substrates.

The scope of this new green MCR was then examined using various commercially or easily available starting materials under conditions B. In particular, we projected to introduce cyclic aromatic and aliphatic diamines in the sequence, in combination with benzaldehyde and $\mathbf{2 a}$ (Figure 1). In the first case, using $o$-aminoaniline (1b), we were not able to isolate the expected 1,4-benzodiazepine 4d. ${ }^{18}$ On the contrary, trans-cyclohexane-1,2-diamine (1c) allowed a quantitative formation of the corresponding heterocycle $\mathbf{4 e}$, isolated with $99 \%$ yield as a single diastereomer bearing four stereogenic centers. In the latter case, the product was isolated with high purity after dilution of the reaction mixture with ethyl acetate and filtration through a short pad of Celite.

On the basis of this excellent result, we synthesized a series of 1,4-diazepines from trans-cyclohexane-1,2-diamine $(\mathbf{1 c})$, in combination with various $\beta$-ketoamides and aromatic aldehydes. ${ }^{19}$ Moderate to quantitative isolated yields of the desired products $\mathbf{4 f}-\mathbf{h}$ could be obtained (Scheme 3 and Figure 2) with a very high level of diastereoselectivity since only the represented stereoisomers were detected in the crude. Although secondary $(\mathbf{2 a}, \mathbf{b})$ or tertiary (2c) amides gave similar results in terms of yield<smiles>Nc1ccccc1N</smiles><smiles>O=C(Nc1ccccc1)C1=C2Nc3ccccc3NC(c3ccccc3)C2CC1</smiles>

$4 d$<smiles>NC1CCCCC1N</smiles>

$1 \mathrm{c}$<smiles>O=C(Nc1ccccc1)C1=C2NC3CCCCC3NC(c3ccccc3)[C@@H]2CC1</smiles>

4 e $(99 \%)$

Figure 1

and stereoselectivity, the presence of the amide function seems to be crucial. Indeed, when Dieckmann ester (2d, $\mathrm{Z}=\mathrm{OEt}$ ) was introduced in the sequence, no formation of the corresponding 1,4-diazepine $\mathbf{4}$ was observed, highlighting the specific reactivity of $\beta$-ketoamides in this MCR. Finally, heteroaromatic aldehydes bearing nitrogen, oxygen, or sulfur atoms could also be introduced in the sequence, leading to the desired products without any lost of efficiency, but in these latter cases a 1.5:1 to $3: 1$ mixture of cis- and trans-stereoisomers of diazepines $4 \mathbf{i}-\mathbf{l}$ were obtained. ${ }^{20}$

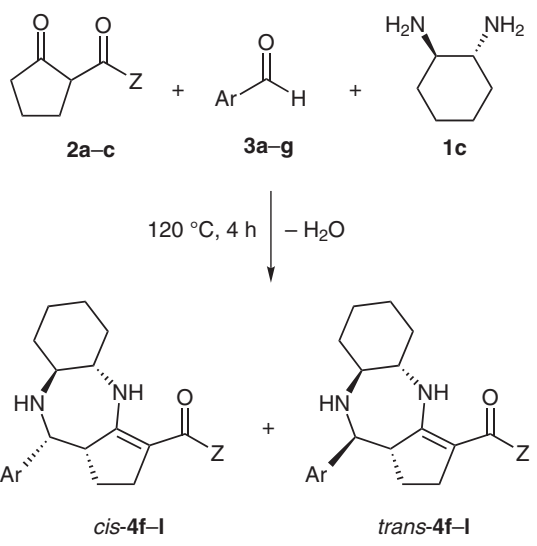

Scheme 3

From a mechanistic point of view, although we did not make systematic investigations, two multistep sequences are currently under exploration. The first one involves a preliminary $\gamma$-functionalization of the starting $\beta$-ketoamide, followed by an aza-Michael addition-intramolecular dehydrative cyclization sequence between the 1,2diamine $\mathbf{1}$ and the $\gamma$-arylidene $\mathbf{5}$. The second possible mechanistic pathway could involve the formation of an intermediate with imine and enamino ester functionalities resulting from the concomitant reaction of $\mathbf{1}$ with $\mathbf{3}$ and $\mathbf{2}$, respectively, which may conduct to the final product via an intramolecular Mannich-type condensation. 


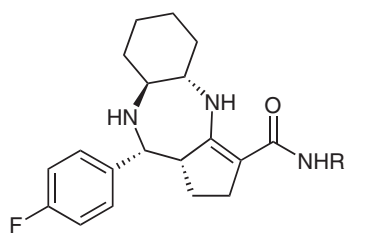

$4 f(\mathrm{R}=\mathrm{Ph}, 99 \%)$

(cis only) (cis only)

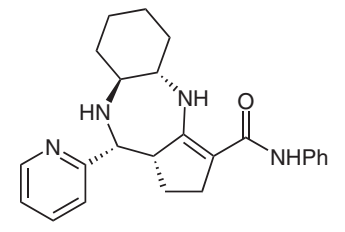

$4 \mathbf{i}(88 \%)$

$($ cis/trans $=1.5: 1)$

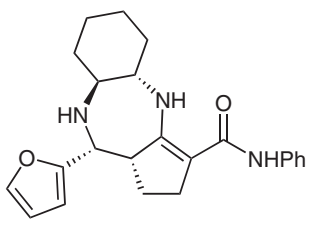

4k $(94 \%)$

$($ cis/trans $=2: 1)$

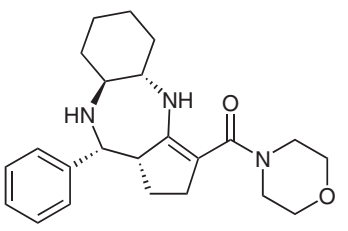

$4 \mathrm{~h}(65 \%)$

(cis only)

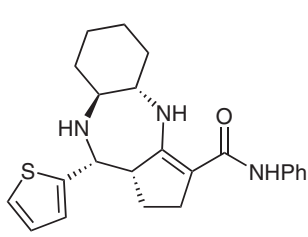

$4 \mathbf{j}(63 \%)$ $($ cis/trans $=3: 1)$

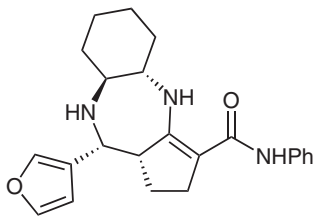

$4 \mathrm{l}(89 \%)$

(cis/trans $=1.5: 1)$ 4g $(\mathrm{R}=t-\mathrm{Bu}, 42 \%)$

Figure 2

In conclusion, we report a green and experimentally simple multicomponent domino sequence for the stereoselective synthesis of 1,4-diazepine derivatives from $\beta$ ketoamides. The sequence does not require any harmful reagents, and liberates water as the only byproduct. Due to its tolerance to various $\beta$-ketoamides, acyclic and cyclic 1,2-diamines, and diverse aromatic aldehydes, this environmentally friendly procedure constitutes a good substrate directed alternative to other previously known methodologies for the synthesis of these heterocycles. ${ }^{21}$

\section{Acknowledgment}

We would like to thank the Ministère de l'Enseignement Supérieur et de la Recherche for providing a one-year post-doctoral fellowship to Dr. Enrique Sotoca.

\section{References and Notes}

(1) (a) Multicomponent Reactions; Zhu, J.; Bienaymé, H., Eds.; Wiley-VCH: Weinheim, 2005. (b) Ramon, D. J.; Yus, M. Angew. Chem. Int. Ed. 2005, 44, 1602. (c) Dömling, A. Chem. Rev. 2006, 106, 17.

(2) (a) Domino Reactions in Organic Synthesis; Tietze, L. F.; Brasche, G.; Gericke, K. M., Eds.; Wiley-VCH: Weinheim, 2006. (b) Padwa, A.; Bur, S. K. Tetrahedron 2007, 63, 5341.

(3) (a) Schreiber, S. L. Science 2000, 287, 1964. (b) Vugts, D. J.; Koningstein, M. M.; Schmitz, R. F.; de Kanter, F. J. J.; Groen, M. B.; Orru, R. V. A. Chem. Eur. J. 2006, 12, 7178. (c) Nielsen, T. E.; Schreiber, S. L. Angew. Chem. Int. Ed. 2008, 47,48 .
(4) Step economy: (a) Wender, P. A.; Baryza, J. L.; Brenner, S. E.; Clarke, M. O.; Gamber, G. G.; Horan, J. C.; Jessop, T. C.; Kan, C.; Pattabiraman, K.; Williams, T. J. Pure Appl. Chem. 2003, 75, 143. (b) Wender, P. A.; Baryza, J. L.; Brenner, S. E.; Clarke, M. O.; Craske, M. L.; Horan, J. C.; Meyer, T. Curr. Drug Discovery Technol. 2004, 1, 1. (c) Wender, P. A.; Gamber, G. G.; Hubbard, R. D.; Pham, S. M.; Zhang, L. J. Am. Chem. Soc. 2005, 127, 2836.

(5) Atom-economy: (a) Trost, B. M. Science 1991, 254, 1471. (b) Trost, B. M. Angew. Chem., Int. Ed. Engl. 1995, 34, 258. (c) Trost, B. M. Acc. Chem. Res. 2002, 35, 695.

(6) For a special issue in environmental chemistry, see: Chem. Rev. 1995, 95, 3.

(7) Tanaka, K. Solvent-Free Organic Synthesis; Wiley-VCH: Weinheim, 2003.

(8) (a) For a special issue in green chemistry, see: Chem. Rev. 2007, 107, 2167. (b) Tucker, J. L. Org. Process Res. Dev. 2006, $10,315$.

(9) For recent reviews on the utilization of 1,3-dicarbonyl derivatives in MCR, see: (a) Simon, C.; Constantieux, T.; Rodriguez, J. Eur. J. Org. Chem. 2004, 4957. (b) LiébyMuller, F.; Simon, C.; Constantieux, T.; Rodriguez, J. QSAR Comb. Sci. 2006, 25, 432.

(10) (a) Simon, C.; Peyronel, J. F.; Rodriguez, J. Org. Lett. 2001, 3, 2145. (b) Simon, C.; Liéby-Muller, F.; Peyronel, J.-F.; Constantieux, T.; Rodriguez, J. Synlett 2003, 2301. (c) Liéby-Muller, F.; Constantieux, T.; Rodriguez, J. J. Am. Chem. Soc. 2005, 127, 17176. (d) Liéby-Muller, F.; Simon, C.; Imhof, K.; Constantieux, T.; Rodriguez, J. Synlett 2006, 1671. (e) Liéby-Muller, F.; Constantieux, T.; Rodriguez, J. Synlett 2007, 1323.

(11) (a) Habib-Zahmani, H.; Hacini, S.; Charonnet, E.; Rodriguez, J. Synlett 2002, 1827. (b) Habib-Zahmani, H.; Viala, J.; Hacini, S.; Rodriguez, J. Synlett 2007, 1037.

(12) (a) Filippini, M. H.; Rodriguez, J. J. Chem. Soc., Chem. Commun. 1995, 33. (b) Charonnet, E.; Filippini, M. H.; Rodriguez, J. Synthesis 2001, 788.

(13) While this work was in progress, a related acid-catalyzed transformation with $\beta$-ketoesters in 1,2-dichloroethane as solvent was reported: Fujioka, H.; Murai, K.; Kubo, O.; Ohba, Y.; Kita, Y. Org. Lett. 2007, 9, 1687.

(14) For recent biological activity investigations with respect to these heterocycles, see for example: Tanaka, T.; Muto, T.; Maruoka, H.; Imajo, S.; Fukami, H.; Tomimori, Y.; Fukuda, Y.; Nakatsuka, T. Bioorg. Med. Chem. Lett. 2007, 17, 3431.

(15) Wender, P. A.; Verma, V. A.; Paxton, T. J.; Pillow, T. H. Acc. Chem. Res. 2008, 41, 40.

(16) Chemical purities were in the range from $80-95 \%$ as estimated by NMR. However, flash chromatography purification resulted in a significant lost of pure product, probably due to unrationalized degradation.

(17) Stereochemistry of the products has been fully studied by 2D NMR analysis, including a detailed analysis of coupling patterns and constants.

(18) A complex mixture of unidentified products was obtained, probably due to degradation of starting materials.

(19) Typical Procedure for the Synthesis of Compounds 4 To a $50 \mathrm{~mL}$ two-necked round-bottomed flask flushed with Ar, equipped with a magnetic stirring bar and a reflux condenser, were added $\beta$-ketoamide $2(1.28 \mathrm{mmol})$, aldehyde $\mathbf{3}$ (1.5 $\mathrm{mmol}$ ), and diamine $\mathbf{1}$ (1.28 $\mathrm{mmol})$. The mixture was stirred at $110^{\circ} \mathrm{C}$ under Ar for $4 \mathrm{~h}$, diluted with EtOAc $(20 \mathrm{~mL})$ after cooling, and filtered through a short pad of Celite. After evaporation, the crude resulting slurry was purified by flash chromatography over $\mathrm{SiO}_{2}$. Selected Physical Data for Compounds 4a Amber oil; $R_{f}=0.7$ (EtOAc). ${ }^{1} \mathrm{H}$ NMR $(300.13 \mathrm{MHz}$, 
$\left.\mathrm{CDCl}_{3}\right): \delta=1.10-1.40(\mathrm{~m}, 1 \mathrm{H}), 1.40-1.60(\mathrm{~m}, 1 \mathrm{H}), 2.10(\mathrm{br}$ $\mathrm{s}, 1 \mathrm{H}), 2.30-2.40(\mathrm{~m}, 2 \mathrm{H}), 2.87(\mathrm{dd}, J=15.0,6.0 \mathrm{~Hz}, 1 \mathrm{H})$, $3.10(\mathrm{dd}, J=15.0,6.0 \mathrm{~Hz}, 1 \mathrm{H}), 3.20-3.30(\mathrm{~m}, 2 \mathrm{H}), 3.42(\mathrm{~d}$, $J=12.0 \mathrm{~Hz}, 1 \mathrm{H}), 3.51(\mathrm{~d}, J=12.0 \mathrm{~Hz}, 1 \mathrm{H}), 6.60(\mathrm{br} \mathrm{s}, 1 \mathrm{H})$, $6.95(\mathrm{t}, J=9.0 \mathrm{~Hz}, 1 \mathrm{H}), 7.10-7.30(\mathrm{~m}, 7 \mathrm{H}), 7.42(\mathrm{~d}, J=9.0$ $\mathrm{Hz}, 2 \mathrm{H}), 8.71(\mathrm{br} \mathrm{s}, 1 \mathrm{H}) .{ }^{13} \mathrm{C}$ NMR $\left(75.47 \mathrm{MHz}, \mathrm{CDCl}_{3}\right)$ : $\delta=26.9,27.4,47.4,51.4,54.1,68.7,94.4,119.6(2 \mathrm{C})$, 123.0, 127.6, 127.7 (2 C), 128.5 (2 C), 128.7 (2 C), 138.8, 143.3, 166.4, 167.0. MS (EI): $m / z(\%)=225(6), 241(43)$ $\left[\mathrm{M}-\mathrm{Ph}^{+}\right], 242$ (9), 334 (100) [M + $\left.\mathrm{H}^{+}\right], 335$ (19).
(20) Although it is not clear at the moment why we observed this loss of stereoselectivity, the two diastereomers were easily separable by flash chromatography.

(21) For recent contributions in this field, see for example:

(a) Iden, H. S.; Lubell, W. D. Org. Lett. 2006, 8, 3425.

(b) Van Brabandt, W.; Vanwalleghem, M.; D'hooghe, M.; De Kimpe, N. J. Org. Chem. 2006, 71, 7083.

(c) Wlodarczyk, N.; Gilleron, P.; Millet, R.; Houssin, R.; Hénichart, J.-P. Tetrahedron Lett. 2007, 48, 2583.

(d) Maruoka, H.; Muto, T.; Tanaka, T.; Imajo, S.; Tomimori, Y.; Fukuda, Y.; Nakatsuka, T. Bioorg. Med. Chem. Lett. 2007, 17, 3435 . 